$\mathbf{R}_{\text {ESEARCH }} \mathbf{P}_{\text {APER }} \longrightarrow \frac{\text { FOOD SCIENCE }}{\text { RESEARCH JOURNAL }}$ e ISSN-2230-9403 Visit us :

www.researchjournal.co.in

Volume 9 | Issue 1 | April, 2018 | 12-19

DOI : 10.15740/HAS/FSRJ/9.1/12-19

\title{
Sensory evaluation and nutritional composition of oat based value added gluten free muffins
}

\author{
Bhawna Mehta and Sudesh Jood
}

\begin{abstract}
Oats provide a useful substitute for wheat products in patients suffering from celiac disease. The incorporation of oats into a gluten free diet diversifies the celiac diet and also provides many health and nutritional benefits. Keeping these facts in view, the present study was undertaken to develop gluten free muffins by utilizing processed (malted, flaked, roasted and popped) and unprocessed oat flour in combinations with rice flour, mung bean flour and linseed powder. It was found that overall organoleptic acceptability of Type-I (unprocessed oat flour based blend), Type-II (malted oat flour based blend) and Type-III (flaked oat flour based blend) muffins were 'liked moderately' by the judges whereas Type-IV and Type-V muffins (i.e. roasted and popped oat flour based blend) were 'liked slightly' by the panelists. Hence, most acceptable (Type-I, Type-II and Type-III) muffins were selected for their physico-chemical and nutritional composition. Water and oil absorption capacity was significantly higher $(2.25$ and $1.94 \mathrm{~g} / \mathrm{g})$ in Type-II muffins as compared to Type-III and Type-I muffins. Whereas, Type-I muffins exhibited higher $(0.65 \mathrm{~g} / \mathrm{ml})$ bulk density. Muffins prepared from Type-II and Type-III blend contained higher albumin (4.48 and 4.32\%), globulin (6.98 and 6.64\%) and glutelin (3.92 and 3.76\%) fractions. Nutritional composition revealed that muffins prepared from malted oat flour based blend had significantly higher amount of protein (16.82\%), available $\mathrm{Ca}(57.78 \%), \mathrm{Fe}(46.30 \%)$ and $\mathrm{Zn}(40.43 \%)$. Total minerals i.e calcium, phosphorus, magnesium, iron and zinc was found to be maximum in Type-I and Type-III muffins. Total and insoluble dietary fibre was higher in Type-I (11.40 and 3.21\%) and Type-III (10.26 and 2.26\%) muffins as compared to Type-II muffins. However, soluble dietary fibre was found to be maximum in muffins prepared Type-II $(4.70 \%)$ and Type-III $(4.61 \%)$ muffins. It may be concluded that oat based gluten free muffins could be suitable for patients suffering from celiac disease.
\end{abstract}

Key Words : Muffins, Sensory evaluation, Dietary fibre, Proximate composition, Minerals

How to cite this article : Mehta, Bhawna and Jood, Sudesh (2018). Sensory evaluation and nutritional composition of oat based value added gluten free muffins. Food Sci. Res. J., 9(1): 12-19, DOI : 10.15740/HAS/FSRJ/9.1/12-19. 